\title{
Retraction Note: Bioinformatics analysis of mountain plant characteristics and ginsenoside glycosyltransferase based on image recognition
}

\author{
Chenyong Lang ${ }^{1} \cdot$ Xin Sui $^{1}$ \\ Published online: 6 December 2021 \\ (c) Saudi Society for Geosciences 2021
}

Retraction Note: Arabian Journal of Geosciences (2021)

14: 1800

https://doi.org/10.1007/s12517-021-08174-0

The Editor-in-Chief and the Publisher have retracted this article because the content of this article is nonsensical. The peer review process was not carried out in accordance with the Publisher's peer review policy. Author Xin Sui has not responded to correspondence regarding this retraction. The Publisher has not been able to obtain a current email address for author Chenyong Lang.

The original article can be found online at https://doi.org/10.1007/ s12517-021-08174-0.

Xin Sui

cylang85@126.com

1 College of Biology and Food Engineering, Jilin Institute of Chemical Technology, Jilin 132022, China 